\title{
Alternância dativa sob a perspectiva da Gramática de Construções: uma análise do verbo senden
}

\author{
Dativ alternations under the view of Constructions Grammar: an analysis of the verb \\ senden \\ http://dx.doi.org/10.11606/1982-88372032180
}

Anna Carolina Heluany ${ }^{1}$

\begin{abstract}
This work presents an analysis of the dative alternance of the verb senden from German language. The theoretical assumptions from the Construction Grammar postulated by GOLDBERG (1995) regarding the ditransitive and its prepositional paraphrase and a verbsensitive approach to the dative alternation by RAPPAPORT HOVAVAND LEVIN (2008) are compared and used as a corpus analysis tool. By means of them, it is analysed whether the constructions constituted by the verb senden and the prepositional syntagma denote an event schemata caused possession or event schemata caused motion. The precepts raised by Adler (2011) in her studies about the dative alternance in German are presented, assisting in the event distinction denoted by the construction. Thus, the realized research reinforces the author's reflections about the new facet of the preposition an that appears in transfer verbs - the addressee-an, supporting the argumentation about the fact that it is not the double object variant or the prepositional syntagma the responsible for the event denoted by the construction, but the arguments that constitute it. This research also proposes another kind of classification for the analysis of German language verbs that denote transfer event in clauses deprived of volitive agent: causal event as transfer (GOLDBERG 1995), in which $X_{\text {CAUSE }} Y$ (AFFECT $_{\text {) to Receive }} Z$ (EFFECT).
\end{abstract}

Keywords: caused possession; caused motion; causal event as transfer

Resumo: Este trabalho apresenta uma análise da alternância dativa do verbo senden da língua alemã. Os pressupostos teóricos da Gramática de Construções postulados por GOLDBERG (1995) no que concerne aos bitransitivos e suas paráfrases preposicionais e a abordagem da sensitividade ao núcleo verbal de RAPPAPORT HOVAV E LEVIN (2008) são comparados e utilizados como ferramenta de análise do corpus.Por meio deles, analisa-se se as construções constituídas pelo verbo senden e o sintagma preposicional an denotam um evento de posse causada ou de movimento causado. Apresentam-se preceitos abordados por Adler (2011) em seus estudos sobre a alternância dativa na língua alemã, que auxiliam na distinção do evento denotado pela construção. Assim, a pesquisa realizada corrobora as reflexões da autora sobre a nova faceta da preposição an que aparece em verbos de transferência - o addressee-an, sustentando sua argumentação sobre o fato de que não são as variantes do objeto duplo (dativo), ou do sintagma preposicional (no caso, an) as responsáveis pelo evento denotado pela

1 Goethe-Institut São Paulo, Rua Lisboa, 974, São Paulo, SP, 05413-001, Brasil. E-mail: carol1orac17@hotmail.com

Este artigo apresenta os principais pontos abordados na dissertação de mestrado da mesma autora (HELUANY, 2016). 
Heluany, A. C. - Alternância dativa

construção, mas sim os argumentos que a constituem. Essa pesquisa também propõe outro tipo de classificação para a análise de verbos da língua alemã que denotam eventos de transferência em orações destituídas de agente volitivo: evento causal como transferência (GOLDBERG

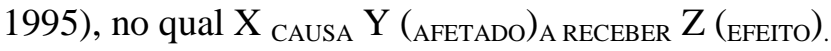

Palavras-chave: construção de movimento causado; construção de posse causada; evento causal como transferência

\section{Introdução}

A literatura sobre o caso dativo como complemento verbal na área da Linguística Alemã (ENGELEN 1975; MATZEL 1976; WEGENER 1985; SuCHAROWSKI 1994, entre outros) aponta o caso como instável, uma vez que este pode ser substituído por outros tipos de complementos, dentre os quais se destacam os sintagmas preposicionais (Ich sende dir eine Email/ Ich sende eine Email an dich).

Conforme Sucharowski (1994), o dativo como objeto é cada vez menos empregado no alemão. O autor do artigo "Der Dativ und seine präpositionalen Varianten als Kasusparaphrasen. Überlegungen zu einem allgemeineren Kasusbegriff” afirma que a análise de textos na língua alemã mostra que o dativo é preterido e substituído por complementos preposicionais.

WEgENER (1985) corrobora a análise de SUCHAROWSKI (1994). Para a autora, essa substituição abrange até mesmo os verbos que tipicamente pedem dativo, como os verbos de transferência de posse e de comunicação:

A coocorrência de construções com o dativo e com o sintagma preposicional apresentase, atualmente, de acordo com a preposição e o tipo de verbo, mais forte do que uma pós-ocorrência diacrônica ou ou uma coocorrência sincrônica [...]. A dissolução parcial do dativo por um PP mostra, junto com a sua substituição pelo acusativo, genitivo e nominativo, uma instabilidade geral do dativo. Entretanto, essas substituições não mostram apenas a "fragilidade"do dativo - segundo o lema "Salvem o dativo"! -, mas também um aumento das possibilidades do dativo de expressar um papel semântico por meio de diferentes NPs com marcação de caso e PPs, sobretudo para realizar distintas topicalizações e focalizações (WEGENER 1985:232-233). ${ }^{2}$

\footnotetext{
${ }^{2}$ As traduções realizadas neste artigo são da autora. Trecho no original: "Das Nebeneinander von Dativund Präpositionalkonstruktionen stellt sich derzeit je nach Präposition und je nach Verb(typ) stärker als diachrones Nach- oder als synchrones Nebeneinander dar. [...] Die partielle Ablösung des Dativs durch eine PP zeigt, zusammen mit seiner Substitution durch Akkusativ, Genitiv und Nominativ, eine generelle Instabilität des Dativs. Jedoch belegt dies nicht nur eine 'Schwäche' des Dativs - nach dem Motto 'Rettet dem Dativ'! -, sondern zeigt zugleich die gesteigerten Möglichkeiten des Dativs, eine semantische Rolle durch unterschiedliche Kasus-NPs und PPs auszudrücken, vor allem um unterschiedliche Topikalisierungen und Fokussierungen vorzunehmen" (WEGENER 1985: 232-233).
} 
Heluany, A. C. - Alternância dativa

Observa-se que, para WEGENER (1985), a substituição de sintagmas nominais no dativo por meio de sintagmas preposicionais deve, mais fortemente do que em outras substituições, ser avaliada como um sinal de "dissolução" do dativo, já que esta pode ser observada numa extensão crescente.

A alternância entre um complemento dativo e um sintagma preposicional que pode ocorrer dentro de alguns verbos do grupo dos bitransitivos é um fenômeno que foi muito estudado na língua inglesa, e chamado, na literatura sobre o tema, de alternância dativa.

A abordagem do significado múltiplo é a classe predominante de análise da alternância dativa na língua inglesa. Segundo RAPPAPORT HOVAV e LEVIN (2008), essa abordagem assume uma relação não derivacional entre a variante do objeto duplo (dativo) e a variante do sintagma preposicional. Assim, cada uma é associada ao seu próprio significado, além de originar a sua própria realização de argumentos.

Alguns linguistas que se dedicaram ao estudo da alternância dativa (RAPPAPORT HovAv; LEVIN 2008; AdLER 2011), cujos trabalhos se enquadram na abordagem do significado múltiplo, valeram-se dos pressupostos teóricos da Gramática de Construções para classificar semanticamente os tipos de eventos que cada variante pode representar.

A perspectiva da Gramática de Construções focaliza a construção sintática em si, e não apenas o verbo. Dessa forma, as construções têm significado próprio e esquemático, independentemente dos verbos e outros itens lexicais que a compõem (cf. FERRARI 2011).

Um dos grandes trabalhos expoentes da Gramática de Construções é o de GOLDBERG (1995). A autora parte da premissa de que as construções refletem cenas básicas das experiências humanas, como posse causadae movimento causado. $\mathrm{Na}$ primeira, tem-se um agente $(\mathrm{X})$ que causa $(\mathrm{Y})$ a receber $(\mathrm{Z})$; na segunda, um agente $(\mathrm{X})$ que causa (Y) a mover para (Z) (cf. GOLDBERG 1995).

Partindo-se dos pressupostos teóricos da Gramática de Construções, este artigo tem como objetivo analisar a alternância de argumentos dativos e sintagmas preposicionais no alemão ocorrentes com o verbo senden em eventos de transferência. Nessas alternâncias, o terceiro participante é expresso por um complemento dativo ou por um sintagma preposicional: Ich sende meiner Mutter Grüße("Eu envio cumprimentos à minha mãe"[dativo]) Ich sende Grüße na meine Mutter("Eu envio cumprimentos à [an, sintagma preposicional] minha mãe"). 


\section{Metodologia}

Para a compilação do corpus deste trabalho foi utilizado o banco de dados de corpora escritos do software COSMAS II, desenvolvido pelo Institut für Deutsche Sprache, de Mannheim. Esse software permite acesso ao corpus de referência (Referenzkorpus DeReko), que consiste num conjunto de corpora em língua alemã composto por mais de 29 bilhões de palavras de textos escritos. Trata-se de textos jornalísticos, científicos e de outros gêneros textuais.

\subsection{Metodologia de análise}

Nesta pesquisa, foi realizada a análise de casos de alternância dativa no alemão com o verbo senden. Para isso, é apresentada uma breve revisão de abordagens sobre a alternância dativa, na língua inglesa e alemã, focando sobretudo na abordagem do significado múltiplo, conforme KRIFKA (1999) e WUNDERLICH (2005). Segundo essa abordagem, cada variante - a variante com o objeto duplo e a com o sintagma preposicional - denota um evento diferente: mudança de posse e de movimento/localização, respectivamente.

Também são apresentados os preceitos básicos da Gramática de Construções discutidos por GolDBERG (1995) referentes aos verbos bitransitivos e suas paráfrases preposicionais, uma vez que muitos trabalhos sobre a alternância dativa se valeram das considerações abordadas por esta autora.

Ainda em se tratando de alternância dativa, também será discutida a análise da sensitividade ao núcleo verbal de RAPPAPORT HOVAV E LEVIN (2008), verificando em que medida os pressupostos das autoras convergem e/ou divergem daqueles discutidos por GOLDBERG (1995), mencionando também questões referentes à inferência de transferência bem-sucedida, que por sua vez é tradicionalmente relacionada à construção com o objeto duplo (dativo).

A análise das teorias e autores é realizada no intuito de reunir ferramentas que possibilitem a classificação das construções do corpus do presente trabalho, conforme o tipo de evento que denotam (posse causada ou movimento causado), sendo descritas e discutidas as dificuldades encontradas ao longo da análise. 
Heluany, A. C. - Alternância dativa

Assim, os objetivos dessa pesquisa são:

1. Classificar as orações do corpus com base nos preceitos da Gramática de Construções de GoldBERG (1995), verificando se os eventos denotados pelas construções são de posse causada ou de movimento causado.

2. Avaliar se as variantes são responsáveis pelo tipo de evento denotado pela construção, ou se existem outros argumentos que licenciam a semântica representada pelas construções.

Ao longo da análise do corpus foram aplicados alguns testes para auxiliar na distinção entre o evento denotado pela construção. Nesses casos, as orações foram reescritas com estruturas diferentes, objetivando avaliar a adequabilidade do teste para a distinção do evento denotado pela construção. Para saber se tais orações poderiam ser ditas em alemão, foram consultados falantes nativos.

\section{Análise}

WUNDERLICH (2005) propõe as seguintes representações semânticas para representar os verbos com os quais os dois eventos mudança de posse e mudança de localização coocorrem $^{3}$ :

Duas classes de verbos bitransitivos:

a. $\mathrm{ACT}(\mathrm{x}) \& \mathrm{BECOME} \operatorname{POSS}(\mathbf{y}, \mathrm{z}) \mathrm{y}$ é um recipiente.

b. ACT(x) \& BECOME LOC $(\mathrm{z}, \mathrm{AT}(\mathrm{y}))$ y é o alvo.

Assim, as orações (1a) e (1b) seriam representantes de mudança de localização, uma vez que são constituídas pelo sintagma preposicional an:

a. Hans Heinrich Lammers (X), Chef der Reichskanzlei, sendet an Rosenberg (Y) im Auftrag von Hitler ein Antwortschreiben (Z) (WDD11/E30.39218: Diskussion:Einsatzstab Reichsleiter In: WikipediaURL:http://de.wikipedia.org/wiki/Diskussion:Einsatzstab_Reichsl eiter_Rosenberg: Wikipedia, 2011).

\footnotetext{
${ }^{3}$ As orações analisadas ao longo da presente seção são um recorte dos principais exemplos apresentados na dissertação de mestrado da mesma autora.
} 
Heluany, A. C. - Alternância dativa

b. Wer (X) für ein soziales Projekt eine finanzielle Unterstützung beantragen möchte, sendet eine kurze Projektbeschreibung (Z) an den Vorsitzenden (Y) (BRZ07/JUN.10686 Braunschweiger Zeitung, 20.06.2007).

Essa análise converge com a proposta de KRIFKA (1999), segundo aqual as construções com sintagma preposicional denotam movimento de um objeto para um alvo. Além disso, analisar as orações supracitadas como eventos de movimento está em conformidade com a proposta de Goldberg (1995), segundo a qual construções com sintagma preposicional e argumento TEMAfísico denotam um evento de movimento causado.

No entanto, analisar orações como as representadas em (2) com base nos preceitos de KRIFKA (1999) e WUNDERLICH (2005) gera questionamentos:

a. Grüße sendet die Klasse $4 \mathrm{a}$ an Clara Butler aus Neuseeland (BRZ06/NOV.07122 Braunschweiger Zeitung, 13.11.2006).

b. Herzliche Grüße an Euch liebe Eltern sendet Euer Otto (BRZ13/JAN.00729 Braunschweiger Zeitung, 03.01.2013).

c. Die Klasse 7c grüßt ihre ehemalige Mitschülerin Kristin Thuet, die gerade erst nach Goslar gezogen ist. Grüße sendet sie auch an alle ihre Freunde, Familien und die Zweitliga-Profifußballer von Eintracht Braunschweig(BRZ07/APR.03745 Braunschweiger Zeitung, 17.04.2007).

Questiona-se se é possível classificar orações que apresentam um argumento TEMA abstrato como evento de movimento, uma vez que Grüße (cumprimentos) não pode percorrer uma trajetória. Por isso, as orações (2a), (2b) e (2c) não foram representadas semanticamente sob o viés de KRIFKA (1999) e WUNDERLICH (2005). Constata-se que as representações semânticas de Krifka e Wunderlich não contemplam adequadamente orações com sintagmas preposicionais constituídas por um argumento TEMA abstrato.

Diante disso, propõe-se a análise dessas orações tendo como base as reflexões de GOLDBERG (1995). Segundo a autora, construções com sintagma preposicional sem movimento no sentido físico são extensões metafóricas da construção de movimento 
Heluany, A. C. - Alternância dativa

causado e semanticamente iguais às construções bitransitivas, apresentando diferença apenas pragmaticamente. Assim, as orações (2a), (2b) e (2c) apresentariam a semântica $\mathrm{X}_{\text {CAUSA }} \mathrm{Y}_{\text {A RECEBER }} \mathrm{Z}$.

As orações (3a), (3b) e (3c), por serem destituídas de agente volitivo, também causam dificuldades na classificação. Analisando-as tendo como base KRIFKA (1999) e WUNDERLICH (2005), estas configurariam movimento de um objeto para um alvo. Entretanto, questiona-se se é possível falar em movimento de um objeto quando não há um agente capaz de aplicar uma força, a qual, por sua vez, acarrete o movimento do argumento TEMA.

a. Der rauschende Beifall sendet ein spezielles Dankeschön an Johan Duijck, den Leiter des Chors.(M06/JAN.03539 Mannheimer Morgen, 16.01.2006; Diskreter Umgang).

b. Die Kleidung sendet nonverbale Signale an jeden Menschen, dem ich begegne. (BRZ06/JUL.07647 Braunschweiger Zeitung, 15.07.2006).

c. Als Spyware wird Software bezeichnet, die persönliche Daten des Benutzers ohne dessen Wissen an den Hersteller der Software oder an Dritte sendet (BRZ06/AUG.07359 Braunschweiger Zeitung, 16.08.2006).

Consoante GoldBerg, o padrão estrutural S V OBJ $\mathrm{OBJ}_{2}$ tem o seu sentido central de transferência concreta estendido de modo a cobrir outros significados. Assim, orações destituídas de agente volitivo podem denotar um evento causal como transferência, como será abordado no tópico "Evento causal como transferência" (cf. GOLDBERG 1995: 67).

\subsection{Recipiente ou alvo? Posse causada ou movimento causado?}

Ao classificar os constituintes que sucedem o sintagma preposicional an, surge a dificuldade de diferenciar em determinadas orações recipiente de alvo e, consequentemente, evento de posse causada de evento de movimento causado.

$\mathrm{Na}$ oração em (4), o argumento an die Zentrale causou dificuldades de classificação. Numa primeira análise, an die Zentrale foi classificado como alvo (goal), 
Heluany, A. C. - Alternância dativa

sendo literalmente o local para onde o alarme é enviado e representando assim uma construção de movimento causado.

(4) Bricht im Haus ein Feuer aus, sendet das Gerät umgehend einen Alarm an die Zentrale, die daraufhin die Feuerwehr alarmiert (M06/OKT.82926 Mannheimer Morgen, 25.10.2006).

A interpretação do constituinte an die Zentrale como alvo corrobora a análise apresentada por Wunderlich acerca dos verbos que denotam um evento no qual mudança de posse e mudança de localizaçãocoocorrem.

A análise proposta por WUNDERLICH (2005) sustenta por sua vez a argumentação de KRIFKA (1999), segundo aqual o sintagma preposicional expressa movimento de um objeto para um alvo, enquanto o frame do objeto duplo implica mudança de posse.

Não obstante, levando-se em consideração as reflexões de GOLDBERG (1995) sobre as construções bitransitivas e suas paráfrases preposicionais, observa-se que o constituinte em questão pode ser visto como um recipiente.

Ao analisar a diferença entre as orações Joe sent Chicago a letter e Joe sent a letterto Chicago, Goldberg afirma que em ambas as orações Chicago deve ser analisado como uma metonímia para as pessoas que moram na cidade. Isso é atribuído a um efeito da construção bitransitiva, tendo em vista que a construção impõe a restrição de que o papel send.goal deve ser um recipiente e, por isso, animado.

Pelo princípio de coerência semântica, Goldberg estabelece que dois papéis são semanticamente compatíveis se um deles pode ser construído como uma instância do outro. O papel de send.goal pode ser construído como um tipo de recipiente, apesar de não ser um recipiente em si (cf. GOLDBERG 1995: 56). Portanto, por este princípio, pode-se analisar "die Zentrale" como recipiente, na medida em que a construção bitransitiva "impõe" que o papel de send.goal seja fundido com o papel de recipiente e interpretado como um ser animado (cf. GOLDBERG 1995: 55).

Contudo, interpretar "an die Zentrale" como recipiente causa estranhamento devido ao contexto no qual tal argumento está inserido, especificamente pelo fato de a oração ser destituída de agente volitivo (das Gerät), sendo, portanto, incapaz de transferir algo para alguém ou para alguma coisa. 


\section{Heluany, A. C. - Alternância dativa}

Este é mais um motivo que causa dificuldades na classificação da oração no que tange a caracterizá-la como um evento de posse causada; ou, por outro lado, como um evento de movimento causado. Essa última classificação pode ser corroborada caso exista a possibilidade de afirmar que o alarme percorre uma trajetória até alcançar um alvo, que nesse caso corresponderia ao sintagma "die Zentrale".

Para RAPPAPORT HOVAV e LEVIN (2008), um recipiente é geralmente uma entidade animada capaz de posse, como corporações, governos e outras organizações qualificadas como "animados estendidos" (cf. RAPPAPORT; LEVIN 2008: 142). No entanto, as autoras não discorrem a respeito de quais constituintes podem ser considerados "animados estendidos". Assim, permanece o questionamento acerca da classificação do evento representado na oração (4), na medida em que classificar "die Zentrale" como recipiente acarreta numa oração excêntrica, e classificá-la como um exemplo de movimento, seguindo as propostas de KRIFKA (1999) e de WUNDERLICH (2005), vai de encontro à proposta de GOLDBERG (1995).

A ausência de um sujeito animado ea ambiguidade concernente à classificação da oração em questão como uma construção de movimento causado, de transferência de movimento causado e de posse causada levantam questionamentos sobre a pertinência de empregar esses dois modelos de eventos (posse causada e movimento causado) na análise dessa oração. Como será visto no tópico "Evento causal como transferência", será sugerido outro modelo de evento para orações destituídas de agente volitivo.

O terceiro argumento da oração presente no trecho reproduzido a seguir também causou dificuldades no momento de análise:

(5) Das Losverfahren an der Uni läuft noch bis 1. September, wer bis dahin ein formloses Schreiben mit Angabe des gewünschten Studiengangs und beglaubigtem Abiturzeugnis an die Uni sendet, kann sich mit viel Glück vielleicht doch noch über eine Zulassung freuen (M06/AUG.68223 Mannheimer Morgen, 30.08.2006; Großer Bewerberandrang an der Uni Mannheim).

Considerando que as pessoas interessadas por uma vaga na universidade devem mandar para a instituição o boletim com as notas da prova Abitur (Abiturzeugnis), temse uma trajetória a ser percorrida pelo documento, enviado pelo correio. Tal fato corrobora a interpretação de um evento de movimento causado, uma vez que o futuro aluno (X) causa o boletim (Y) a mover-se para a universidade (Z). Essa análise 
Heluany, A. C. - Alternância dativa

converge com a proposta de KRIFKA (1999) e de WUNDERLICH (2005), segundo os quais a construção com o sintagma preposicional representa movimento e, desta forma, o terceiro argumento seria o alvo, mas não o recipiente da oração.

Além disso, tal análise está em conformidade com a proposta de GOLDBERG (1995). Para a autora, levando-se em consideração que há movimento no sentido físico, uma vez que o boletim estava em posse do futuro aluno e é deslocado para a universidade, a construção acima representaria um evento de movimento causado, no qual o futuro aluno $(\mathrm{X})$ move o boletim $(\mathrm{Y})$ para a universidade $(\mathrm{Z})$.

Entretanto, essa análise diverge da proposta de ADLER (2011), segundo a qual todas as construções com verbos pertencentes ao grupo prototípico enviarcom sintagma preposicional na denotam um evento de posse causada. Segundo a autora, a preposição na perde seu componente espacial nos verbos que denotam transferência e o componente mudança de localização faz parte do radical verbal e não da variante.

Diante das possíveis análises, questiona-se se a oração em (5) representa um evento de posse causada ou de movimento causado, e, por isso, faz-se necessário analisar qual proposta - se a proposta de KRIFKA (1999) e WUNDERLICH (2005), de GOLDBERG (1995), a de RAPPAPORTHOVAVe LEVIN(2008) ou a de ADLER (2011) - é mais adequada para dar conta de todos os casos.

Para GOLDBERG (1995), como mencionado acima, os recipientes podem aparecer como sintagmas oblíquos em construções de transferência de movimento causado, $o$ que ela elucida por meio da oração Sam gave the piece of land to his son(“Sam deu o pedaço de terra para o seu filho"). A dificuldade encontrada na análise das orações que constituem o corpus deste trabalho consiste no fato de a autora citar apenas um exemplo de recipiente com sintagma oblíquo, sendo este um ser animado, o que por sua vez promove o questionamento sobre a possibilidade de que os constituintes que ocorrem após o sintagma oblíquo sejam considerados recipientes mesmo quando estes são inanimados.

Considerando o exemplo de Chicago citado por GoldBerg (1995: 55), a resposta seria positiva. Entretanto, afirmar que a construção bitransitiva impõe que o alvo seja um recipiente construído por meio de uma metonímia e, por isso, um ser animado, torna a análise das orações subjetiva, pois, levando-se em consideração que tanto GOLDBERG (1995) quanto RAPPAPORT HOVAV e LEVIN (2008) defendem que a construção com o sintagma preposicional pode representar semanticamente um evento 
Heluany, A. C. - Alternância dativa

no qual $\mathrm{X}_{\text {CAUSA }} \mathrm{Y}_{\text {A RECEBER }} \mathrm{Z}$, torna-se fundamental diferenciar com clareza e exatidão alvo de recipiente, inanimado de animado.

A dificuldade para tal diferenciação concerne à questão de que tanto as construções apresentadas por GOLDBERG (1995) para justificar a leitura de um recipiente quanto aquelas fornecidas por RAPPAPORT HOVAV e LEVIN (2008), que demonstram que construções com sintagma preposicional podem apresentar os dois tipos de eventos, são exemplos que apresentam constituintes nos quais os papéis temáticos, no caso, recipiente e alvo, são facilmente identificados.

RAPPAPORT HOVAV e LEVIN (2008), ao citarem o verbo send do inglês como exemplo de verbo que permite um leque amplo de preposições espaciais quando empregado com um tema animado (cf. RAPPAPORT HOVAV; LEVIN 2008: 136), como em Terry sent Pat behind the housel into the attic/out of the room, afirmam que tais usos de send envolvem tipicamente um significado de movimento causado, instanciando provavelmente um sentido levemente diferente do verbo, no qual uma entidade animada induz uma segunda entidade a ir para alguma localização.

As mesmas questões concernentes à diferenciação de recipiente VERSUS alvo e os respectivos tipos de eventos são levantadas na análise da oração em (6):

(6) Gerade erst ist der kanadische EHC-Neuzugang Seamus Kotyk in Wolfsburg angekommen, und schon sendet er die ersten E-Mails an die Heimat (BRZ06/SEP.02375 Braunschweiger Zeitung, 05.09.2006).

Salientando as propostas de KRIFKA (1999) e de WUNDERLICH (2005), tem-se em an die Heimat um alvo e, portanto, a oração expressa um evento de movimento, no qual Seamus (X) causa os e-mails (Y) a se moverem para sua pátria (Z). A trajetória se dá no ciberespaço. Todavia, analisando-se a oração com base em GoLDBERG (1995), "Heimat" seria interpretado como uma metonímia para as pessoas que fazem parte do círculo social de Seamus, constituindo deste modo um recipiente e, assim, a construção representaria semanticamente um evento de posse causada, no qual Seamus (X) causa a pátria (Y - os amigos dele que lá estão) a receber os e-mails (Z), o que está em conformidade com a proposta de ADLER (2011), segundo a qual construções com sintagma preposicional com verbos do grupo enviar denotam sempre posse causada.

A dificuldade para classificar os constituintes ocorrentes após o sintagma preposicional an não se restringe aos exemplos discutidos nas orações anteriores. Orações nas quais os constituintes se referem a partes do corpo humano foram, num primeiro momento, 
Heluany, A. C. - Alternância dativa

classificados como alvo. Entretanto, a análise mais minuciosa de orações como em (7) e (8) pode contradizer essa primeira análise:

(7) Das verkürzte Protein aber kann bakterielle Bestandteile nur ungenügend erkennen und sendet zu wenig chemische Botenstoffe an das Immunsystem (NUN01/AUG.00024 Nürnberger Nachrichten, 01.08.2001).

(8) Die Kapsel sendet ständig Aufnahmen aus dem Körperinnern an sechs Sensoren, die zuvor auf den Bauch des Patienten geklebt wurden(M02/JAN.04233 Mannheimer Morgen, 17.01.2002).

A análise desses exemplos mostra que classificar an das Immunsystem ("para o sistema imunológico") e na sechs Sensoren ("para seis sensores") como alvo talvez não seja a análise mais adequada, tendo em vista que ambas orações são destituídas de agente volitivo e, por sua vez, não apresentam um sujeito animado capaz de lançar algo a movimento (o que denotaria um evento de movimento causado) ou possuidor de algo denotando um evento de posse causada). Nota-se, mais uma vez, que a questão concernente aos papéis temáticos e argumentais se revela mais complexa no momento em que são utilizados constituintes não "tradicionais", ou seja, não humanos ou animados, como os mencionados anteriormente.

Após a análise das orações que constituem o corpus deste trabalho, notou-se que não é possível definir se determinada construção representa um evento de movimento causado ou de posse causada sem ter em mente uma definição bem clara dos conceitos de alvo e recipiente, assim como de animado e inanimado, uma vez que esses conceitos estão diretamente relacionados ao tipo de evento que uma construção representa.

Diante disso, torna-se necessário retomar brevemente algumas questões referentes aos papéis temáticos.

É possível afirmar que as propostas referentes aos papéis temáticos e à sua hierarquia se complementam (cf. SOARES; MENUZZI 2010: 16), o que permite refletir sobre a dificuldade de se estabelecer uma classificação dos diferentes papéis que podem ser associados ao caso dativo. Isso porque três domínios conceituais estão associados a esse caso, os quais, por sua vez, correspondem aposse; experienciador e localização (cf. ADLER2011: 3). 


\section{Heluany, A. C. - Alternância dativa}

Conforme demonstrado anteriormente, é ambíguo, em muitas orações, diferenciar entre recipiente e alvo. Isso se deve ao fato de o recipiente apresentar um papel complexo, que pode ser conceituado como o alvo humano (ADLER 2011: 3), o qual realiza a conexão entre a posse e a localização; ou, por outro lado, entre a mudança de posse e a direção (cf. ADLER2011: 3).

As duas interpretações (recipiente ou alvo) acerca dos referentes do sintagma preposicional an são previstas pela valência do verbo senden. A consulta ao dicionário E-VALBU do Institut für Deutsche Sprache Mannheim mostra que o verbo senden é empregado com o dativo ou com advérbio de direção, indicando o primeiro para quem algo é enviado, ou seja, quem é o recipiente do verbo, e o segundo, o alvo da oração.

Observa-se pela valência associada ao verbo senden que os complementos que sucedem o sintagma preposicional an são classificados como um caso adverbial, $(K a d v)$, o qual indica a direção para onde algo é enviado.

Tendo como base a valência do verbo exposta no dicionário $E-V A L B U$, todas as construções com o sintagma preposicional an denotariam um evento de movimento causado, o que vai de encontro aos pressupostos de GOLDBERG (1995), RAPPAPORT Hovav e LEVIN (2008) e AdLER (2011).

A função central do papel do recipiente e sua relação com os conceitos de posse e localização são ilustradas no mapa semântico de línguas europeias das funções do caso dativo (FIG.1).

Os papéis presentes no mapa representam o inventário universal das funções do dativo para línguas que têm a codificação do tipo dativo (codificações preposicionais incluídas). Papéis ligados (indicados por hífen) devem ser lidos de forma semelhante às hierarquias implicacionais: Por exemplo, é implausível que uma língua inclua os papéis direção e beneficiário sem incluir o papel recipiente no seu inventário das funções do dativo. Desta maneira, o mapa mostra que o recipiente, uma vez que tem o maior número de conectores a outros papéis (localização, experienciador e posse), deverá ser o papel mais comum nas codificações dativas (cf. ADLER2011:4). 


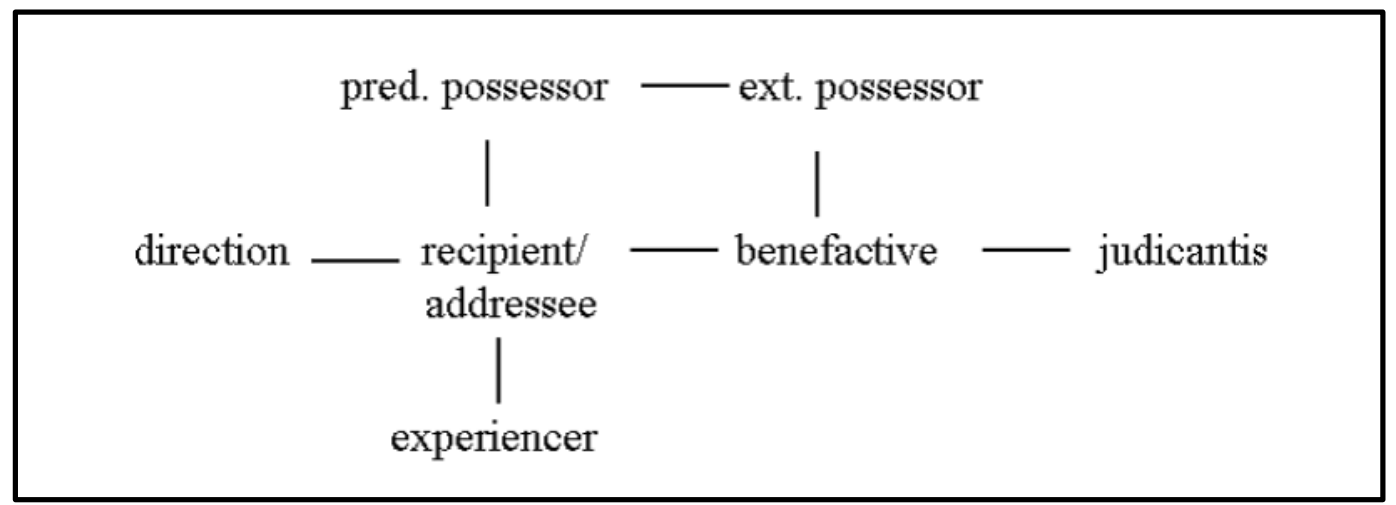

Figura 1: Mapa semântico de línguas europeias das funções do caso dativo Fonte: HASPELMATH1999 apud ADLER 2011: 4.

$\mathrm{Na}$ análise do corpus desta pesquisa, foram apresentados exemplos que corroboram a dificuldade de diferenciação entre possee localização, e entre recipiente e alvo. Isso confirma a observação de Adler (2011) sobre o desafio de se analisar apropriadamente os três domínios conceituais de posse, localização eexperienciador (ADLER 2011: 4).

Somando-se aos exemplos a análise de outros trabalhos baseados na Gramática de Construções, é possível constatar que a presente pesquisa não é a única a se confrontar com a complexidade da definição de recipiente.

ZIEM e LASCH (2013) citam o exemplo dado por GOLDBERG (1995) com o verbo send - Joe sent Chicago a letter, no qual o verbo é analisado a respeito do seu significado como uma instância do significado da construção. No exemplo de Goldberg (1995), Chicago é o recipiente de uma carta, e é visto metonimicamente como os moradores da cidade ou também como uma instituição da cidade. Segundo os autores, a diferenciação semântica entre o papel de recipiente e o de alvo é prejudicada nessa análise, uma vez que o verbo não disponibiliza esse papel, e uma fusão do papel argumental receiver com o papel participante send.goal não pode ser efetuada, como pode ser observado na representação da construção com o verbo senden exposta por GOLDBERG (1995): 


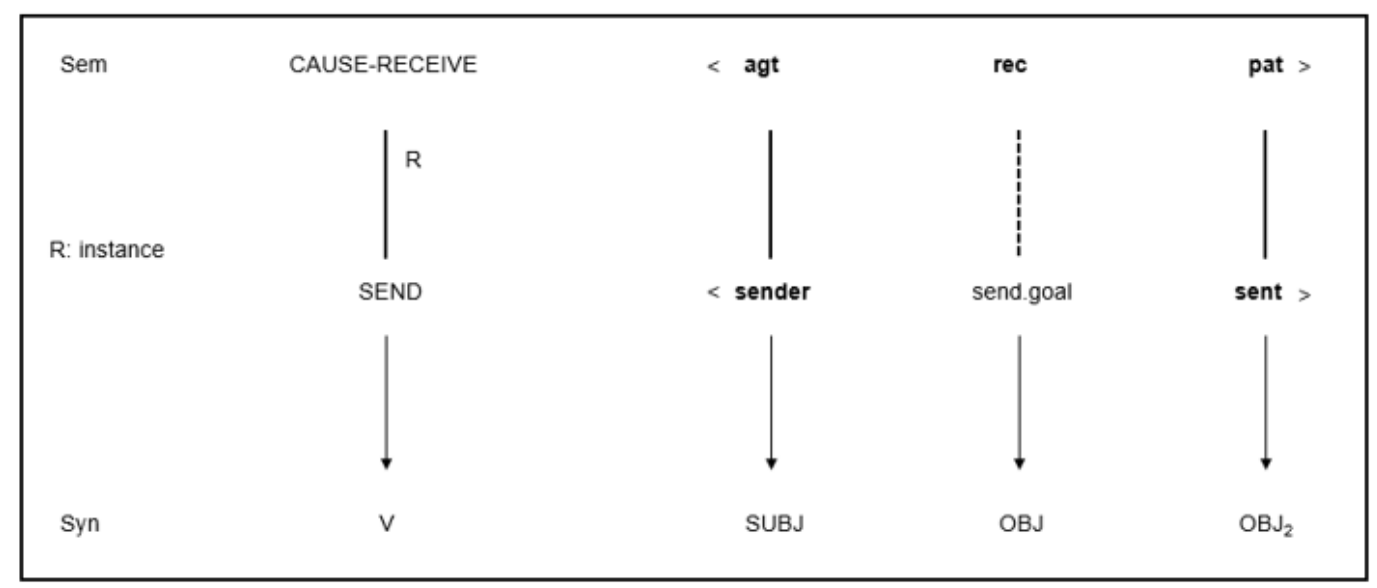

Figura 2: Verbo send na construção bitransitiva

Fonte: GOLDBERG1995: 55.

A linha pontilhada abaixo do papel argumental recipiente indica que o papel participante não obrigatório send.goal herda o status de papel perfilado da construção, mas não do verbo.

ZIEM e LASCH (2013) apontam alguns problemas na análise de GOLDBERG (1995). De acordo com GoldBerg (1995), através da construção é condicionado o modo de leitura que dá preferência a um recipiente animado e isso é um efeito da construção bitransitiva, uma vez que ela impõe a restrição de que o papel send.goal tem de ser um recipiente e, por isso, animado.

A leitura que dá preferência a um recipiente animado é justificada por GOLDBERG (1995) pelo processo de "coerção". Segundo a autora, a "coerção" somente é possível quando a construção requer uma interpretação particular (GOLDBERG 1995: 159). Para Ziem e Lasch, tendo em vista a valência do verbo senden, o papel participante send.goal postulado por Goldberg pode ser entendido como complemento. Contudo, segundo os autores, a representação de Goldberg não deixa explícito se o papel participante se correlaciona com o papel semântico de receiver (presumindo que Chicago é interpretado metonimicamente como uma instituição ou algo da cidade) ou se o alvo em si não pode ser colocado como papel semântico (cf. ZIEM;LASCH 2013: 115).

Conforme demonstrado ao longo da análise, a diferenciação entre evento de posse causada e evento de movimento causado é dificultada pelo fato de não haver uma definição clara de recipiente/alvo, animado/inanimado. ZIEM e LASCH (2013) também se confrontam com essas indagações ao estudarem as premissas de Goldberg 
Heluany, A. C. - Alternância dativa

(1995). Consoante os linguistas, tendo em vista que Goldberg parte do princípio de que o papel participante não obrigatório send.goal do verbo senden herda o status perfilado de papel argumental recipiente através da construção, indaga-se se não é possível diferenciar melhor alvo de recipiente e assim distinguir diferentes tipos de construções numa rede de construções.

Devido às dificuldades encontradas para distinguir recipiente de alvo, buscaram-se na literatura sobre o dativo testes para sustentar a premissa de que o dativo representa o recipiente. WEGENER (1985), em Der Dativ im heutigen Deutsch, expõe o teste do Bekommen-Passiv, apresentado no próximo tópico.

\subsection{Bekommen-Passiv}

WEGENER (1985) sustenta a hipótese de que o referente animado dos sintagmas preposicionais an e $z u$ apresenta apenas o destinatário (den Adressaten), enquanto o complemento dativo apresenta o recipiente (den Empfänger). A autora afirma que é possível comprovar isso pelo teste do Bekommen-Passiv (cf. WEGENER 1985: 224).

Antes da apresentação do teste empregado por WEGENER (1985), é importante ressaltar uma observação em relação aos termos utilizados pela autora para descrever os constituintes que seguem o sintagma preposicional an e os constituintes representados pelo complemento dativo (destinatário VERSUS recipiente). Entende-se que Wegener se refere ao destinatário como o alvo da construção e, desta forma, as construções com o sintagma preposicional an seriam representantes de eventos de movimento causado. Embora a autora não utilize os pressupostos teóricos da Gramática de Construções, tal interpretação é plausível tendo em vista que, para ela, o sintagma dativo é definido como o participante de uma ação de transação (Teilnehmereiner Transaktionshandlung), enquanto a oração com sintagma preposicional representa o destinatário de um transporte (in der P-Konstruktionehereinen Transport) (cf. WEGENER 1985: 227).

De acordo com WEGENER (1985), apenas as construções com dativo permitem a formação de uma paráfrase Bekommen-Passiv.

Ou seja, conforme a autora, denotar o recipiente com um sintagma preposicional an não é gramatical na paráfrase com o verbo bekommen. Este resultado 
Heluany, A. C. - Alternância dativa

mostraria que a pessoa denotada pelo sintagma preposicional an não é um recipiente real.

Objetivando avaliar se o teste da Bekommen-Passiv auxilia na distinção entre recipiente e alvo, ele será aplicado em algumas construções mencionadas anteriormente:

[...] sendet das Gerät umgehend einen Alarm an die Zentrale.

Die Zentrale bekommt (vom Gerät) einen Alarm gesendet.

[...] wer bis dahin ein formloses Schreiben mit Angabe des gewünschten Studiengangs und beglaubigtem Abiturzeugnis an die Uni sendet.

Die Uni bekommt ein formloses Schreiben mit Angabe des gewünschten Studiengangs und beglaubigtem Abiturzeugnis gesendet.

[...] und schon sendet er die ersten E-Mails an die Heimat.

Die Heimat bekommt die ersten E-Mails gesendet.

Com o intuito de analisar a adequabilidade do teste da Bekommen-Passiv para a identificação do recipiente da oração, as orações acima foram reescritas com o complemento dativo:

$(4, ')$

[...] sendet das Gerät umgehend einen Alarm an die Zentrale.

[...] sendet das Gerät der Zentrale umgehend einen Alarm.

$\left(5^{\prime \prime \prime}\right)$

[...] wer bis dahin ein formloses Schreiben mit Angabe des gewünschten Studiengangs und beglaubigtem Abiturzeugnis an die Unisendet.

[...] wer bis dahin der Uni ein formloses Schreiben mit Angabe des gewünschten Studiengangs und beglaubigtem Abiturzeugnis sendet.

$(6, ")[\ldots]$ und schon sendet er die ersten E-Mails an die Heimat. 
Heluany, A. C. - Alternância dativa

[...] und schon sendet er der Heimat die ersten E-Mails.

O fato de ser possível reescrever as orações com o complemento dativo levanta algumas questões. Em primeiro lugar, questiona-se se as orações com o sintagma preposicional na podem ser reescritas com o Bekommen-Passiv.

Partindo-se da premissa de WEGENER (1985), para a qual apenas as construções com dativo permitem a formação de uma paráfrase Bekommen-Passiv, observa-se que não é possível identificar nas orações supracitadas com bekommen se elas são passivas da construção com o sintagma dativo ou do sintagma preposicional.

Numa escala de 1 a 3 , sendo $1=$ impossível, 2 = pouco possível e 3 = possível de serem ditas por um falante nativo, algumas das orações com bekommen citadas anteriormente foram mostradas para falantes nativos. Todas as orações apresentadas aos falantes foram avaliadas como possíveis ou pouco possíveis, nenhum informante considerou as orações com bekommen impossíveis.

No entanto, tendo em vista que, como apresentado nos exemplos, é possível empregar tanto o sintagma dativo quanto o preposicional nas orações citadas, não é possível dizer se a oração apassivada é referente à oração com o sintagma preposicional ou à oração com o sintagma dativo. Por isso, indagar falantes nativos acerca da gramaticalidade dessas orações com bekommen não permite concluir se o teste do Bekommen-Passiv é válido ou não para orações com verbo senden com complemento preposicional.

Para Wegener (1985), uma vez que a oração Otto schickt das Paketan Anna ab não pode ser reescrita com o sintagma dativo (*Otto schickt Anna das Paketab), ela não pode ser apassivada (*Anna bekommt (von Otto) ein Paketabgeschickt)0 (cf. WEGENER 1985: 224). Levando-se em consideração essa afirmação, foi feito um novo teste do Bekommen-Passiv, desta vez com um complemento correspondente a um endereço eletrônico, o qual é realizado apenas com o sintagma preposicional an:

a. Mariana sendeteine E-mail an carol_lorac17@hotmail.com.

b. *Mariana sendet carol_lorac17@ hotmail.com eine E-mail.

Tendo em vista que essa oração só é possível com complemento preposicional, questionaram-se os informantes alemães sobre a probabilidade de falantes nativos produzirem a oração em (10): 
Heluany, A. C. - Alternância dativa

(10) Carol_lorac17@hotmail.com bekommt eine Email gesendet.

Uma vez que orações com o endereço eletrônico aparecem somente com o sintagma preposicional an, mas não com o sintagma dativo, poder-se-ia dizer que, neste caso, o teste corrobora a afirmação de Wegener de que apenas orações com o sintagma dativo podem ser apassivadas, pois foi unânime a resposta 1 (impossível) para essa oração.

ADLER (2011) menciona o teste do Bekommen-Passiv empregado por WEGENER (1985). Segundo ela, esse teste é problemático por dois motivos. Primeiramente, WEGENER (1985) tem como pressuposto que a oração com bekommen é uma passiva regular da construção dativa e que o sintagma preposicional an como sujeito é descartado, pois sintagmas preposicionais não podem ser apassivados. Por esta razão, o teste do Bekommen-Passiv não seria válido para a variante com o sintagma preposicional an. Entretanto, para ADLER (2011), a oração * Sie hat das Buch an sie geschickt bekommen seria a passiva da sentença Er hat ihr ein Buch an sie geschickt (ADLER2011: 187) e causa estranhamento tanto na versão ativa quanto na passiva.

À vista disso, ADLER (2011) indaga se o teste não seria válido se Sie hat das Buch geschickt bekommen fosse uma paráfrase para ambas variantes (Er hat ihr ein Buch geschickt/ ein Buch an sie geschickt). Adler considera que sim, pois não vê uma diferença semântica a respeito do papel da pessoa denotada na variante com an e no sujeito da oração bekommen. Para a autora, tanto a variante com o sintagma dativo quanto a outra com o sintagma an podem ser vistas pelo final, denotando uma transferência bem-sucedida da pessoa pegando o livro (cf. ADLER 2011: 186-187).

Entende-se o questionamento de Adler sobre a possibilidade de a construção Sie hat ein Buch geschickt bekommen ser a passiva da variante com o sintagma dativo e da variante com o sintagma preposicional. Contudo, o fato de a oração *Carol_lorac17@hotmail.com bekommt eine Email gesendet não ser possível na língua alemã contradiz o que ADLER (2011) sugere. É necessária uma pesquisa mais ampla com diferentes construções que podem ser empregadas apenas com o sintagma preposicional e não com o sintagma dativo para poder afirmar se a proposta de Wegener ou a de Adler é mais adequada.

WEGENER (1985) também afirma que na construção passiva a ação de transação (Transationshandlung) é vista do seu fim, ou seja, do recipiente. Por outro lado, a ação de transporte (Transporthandlung) não pode ser vista do seu alvo, uma 
Heluany, A. C. - Alternância dativa

vez que ela não abrange o alvo, mas somente a direção dele (cf. WEGENER 1985: 227). Diante disso, a autora afirma que para a ação de transporte (ou seja, a construção com o sintagma preposicional) fica aberto se o alvo é alcançado (cf. WEGENER 1985: 228).

Assim, observa-se que a premissa de Wegener converge com a proposta de GOLDBERG (1995), segundo a qual a variante com o sintagma dativo implica transferência de posse bem-sucedida, enquanto na variante com o sintagma preposicional não há essa implicatura (GOLDBERG 1995: 33). Por outro lado, a premissa de Wegener (1985) diverge da proposta de RAPPAPORT HOVAV e LEVIN (2008), segundo a quala inferência de transferência bem-sucedida não é resultado de uma variante ou de outra, mas sim do significado lexicalizado no radicalverbal.

RAPPAPORT HOVAV e LEVIN (2008) demonstram, por meio de diferentes exemplos, que quando a transferência bem-sucedida é implicada por um verbo, a implicatura aparece tanto na variante toquanto na variante do objeto duplo. Já se a implicatura de transferência está ausente no verbo, a sua ausência se dá em ambas as variantes (cf. RAPPAPORTHOVAV; LEVIN 2008: 146).

Em relação à inferência de transferência bem-sucedida, concorda-se nessa pesquisa com RAPPAPORT HOVAV e LEVIN (2008), uma vez que, ao se levar em consideração orações com o verbo senden, observa-se que não é possível afirmar recebimento em nenhuma das variantes:

(11) Myriam sendet Briefe aus Holland an Blasi (A97/DEZ.40542 St. Galler Tagblatt, 10.12.1997), aber wegen des Post-Streiks hat Blasi die Briefe nicht bekommen.

(12) Myriam sendet $\underline{\text { Blasi }}$ Briefe aus Holland (A97/DEZ.40542 St. Galler Tagblatt, 10.12.1997), aber wegen des Post-Streiks hat Blasi die Briefe nicht bekommen.

As orações em (11) e (12) corroboram a afirmação de RAPPAPORT HOVAV e LEVIN (2008) sobre o fato de os verbos do grupo enviar implicarem mudança de localização, mas não mudança de posse. Quando algo é enviado, a ideia é que o objeto chegue a um destino, mas a sua chegada não é implicada. Apenas a mudança de localização é implicada, na medida em que algo não pode ser enviado sem que ocorra uma mudança na sua localização (cf. RAPPAPORTHOVAv;LEVIN 2008: 135). 
Heluany, A. C. - Alternância dativa

Ademais, as orações (11) e (12) geram questionamentos acerca dos pressupostos teóricos de KRIFKA (1999) e WunDERLICH (2005), uma vez que para esses autores a variante com o sintagma preposicional denota um evento de movimento, enquanto a variante com o complemento dativo denota transferência. Conforme demonstrado, as orações em (11) e (12) corroboram a argumentação de RAPPAPORT HOVAV e LEVIN (2008) sobre a questão da inferência de transferência bem-sucedida ser devido ao radical verbal e não à variante.

As únicas diferenças observadas no que se refere às duas variantes dizem respeito à estrutura informacional. Num contexto no qual se pergunta para quem algo foi enviado, a construção com o sintagma preposicional pode ser preferida por apresentar o conhecido (Bekanntes) antes do novo (Unbekanntes). Por outro lado, a construção com o complemento dativo apresenta o novo antes do conhecido (PP: Anna sendeteineEmailan Mariana / Dativo: Anna sendet Mariana eineEmail) e, por isso, pode ser preterida. Como explica MusAn (2010), no Mittelfeld da língua alemã há uma preferência clara por colocar o conhecido antes do novo (cf. MUSAN 2010: 53).

Diante disso, é possível perceber que esse teste é insuficiente para sanar a lacuna concernente à definição do papel de recipiente, e, por consequência, não contribui para a diferenciação entre eventos de posse causada e de movimento causado. Entretanto, a análise do teste Bekommen-Passiv apresentado por WEGENER (1985) é importante por permitir reflexões acerca da inferência de transferência bem-sucedida e, por sua vez, o concatenamento das premissas de diversos autores a respeito (KRIFKA 1999; Goldberg 1995; Wunderlich 2005; Rappaport Hovav; Levin 2008; Adler 2011).

Mediante o exposto, nota-se a necessidade de estudos aprofundados sobre o teste do Bekommen-Passiv, objetivando avaliar se ele de fato só pode ser empregado em construções que possuem um sintagma dativo e para as quais não há oração equivalente com o sintagma preposicional, ou seja, se a premissa de WEGENER (1985) está correta, ou se ADLER (2011) tem razão ao considerar a oração apassivada uma oração passiva da construção com o sintagma dativo e da construção com sintagma preposicional.

O fato de a mudança de localização fazer parte do radical do verbo, e não da construção, prova e reforça a dificuldade em distinguir entre posse causada e movimento causado nas orações apresentadas no tópico "Recipiente ou alvo? Posse causada ou movimento causado?”, uma vez que o componente mudança de localização 
Heluany, A. C. - Alternância dativa

é inerente aos verbos do grupo enviar e, sendo assim, a ideia de movimento estará presente em todas as construções constituídas por verbos deste grupo.

Buscando diferenciar entre evento de posse causada e evento de movimento causado com verbos pertencentes ao grupo enviar, ADLER (2011) propõe outro teste, a ser abordado no próximo tópico.

\subsection{HIN-Test}

Conforme mencionado anteriormente, as orações nas quais o terceiro complemento é constituído por uma parte do corpo humano causaram dificuldades de análise, na medida em que é possível interpretar o terceiro constituinte como alvo ou recipiente.

Segundo AdLER (2011), o fato de o sintagma preposicional an locativo ser usualmente incompatível com complementos animados cria uma lacuna semântica que é preenchida pelo addressee-an.

A autora propõe o HIN-Test para diferenciar entre o na locativo e o addresseean. O segundo não pode ser dependente do adverbial hin, advérbio de direção, o qual, por sua vez, adiciona ou fortalece um elemento de trajetória que é presente não só em eventos espaciais, mas também em eventos não espaciais. Dessa forma, é gramatical com $z u$ e, com $z u$, mesmo em uma situação de transferência com um animado, é ainda um alvo espacial. Contudo, com an é somente gramatical com o an puramente espacial, mas não com o addressee-na (cf. ADLER 2011).

A partir dessas considerações, buscou-se reanalisar as orações (4), (5), (6)e (7) tendo como base esse teste, objetivando observar se é possível diferenciar um evento de movimento causado de um evento de posse causada nesses casos:

a. [...] sendet das Gerät umgehend einen Alarm an die Zentrale, die daraufhin die Feuerwehr alarmiert (M06/OKT.82926 Mannheimer Morgen, 25.10.2006).

b. [...] sendet das Gerät umgehend einen Alarm an die Zentrale hin, die daraufhin die Feuerwehr alarmiert. 
Heluany, A. C. - Alternância dativa

a. [..] wer bis dahin ein formloses Schreiben mit Angabe des gewünschten Studiengangs und beglaubigtem Abiturzeugnis an die Uni sendet, kann sich mit viel Glück vielleicht doch noch über eine Zulassung freuen (M06/AUG.68223 Mannheimer Morgen, 30.08.2006; Großer Bewerberandrang an der Uni Mannheim).

b. [...]wer bis dahin ein formloses Schreiben mit Angabe des gewünschten Studiengangs und beglaubigtem Abiturzeugnis an die Uni hin sendet.

(6")

a. Gerade erst ist der kanadische EHC-Neuzugang Seamus Kotyk in Wolfsburg angekommen, und schon sendet er die ersten E-Mails an die Heimat (BRZ06/SEP.02375 Braunschweiger Zeitung, 05.09.2006).

b. $\quad$ und schon sendet er die ersten E-Mails an die Heimat hin.

a. Das verkürzte Protein aber kann bakterielle Bestandteile nur ungenügend erkennen und sendet $\mathrm{zu}$ wenig chemische Botenstoffe an das Immunsystem.

b. Das verkürzte Protein aber kann bakterielle Bestandteile nur ungenügend erkennen und sendet zu wenig chemische Botenstoffe an das Immunsystem hin.

Todos os informantes alemães consultados foram unânimes ao afirmar que nenhuma das orações acima pode ser reescrita com o advérbio direcional hin. Alguns comentaram inclusive o fato de muitas das orações poderem ser escritas com o sintagma preposicional zu em vez do sintagma an e, assim, o acréscimo do advérbio de direção hin seria possível. Isso corrobora a premissa de Adler, a qual explica que o advérbio hin é gramatical com o sintagma $z u$, mas agramatical com o addressee an.

Como AdLER (2011) elucida, o advérbio hin, por ser um locativo que denota direção, indica um evento de movimento causado. Por conseguinte, uma vez que as orações acima não podem ser reescritas com ele, elas indicariam um evento de posse causada, como será sistematizado no próximo tópico. 


\subsection{Eventos de posse causada}

Conforme mencionado no tópico HIN-Test, as orações (4), (5), (6) e (7) foram submetidas ao HIN-Test e, por não poderem ser reescritas com o advérbio locativo hin, denotam um evento de posse causada.

Entretanto, mesmo após constatar por meio do HIN-Test proposto por Adler que tais orações não denotam movimento causado, algumas orações continuaram causando questionamentos.

No item "Recipiente ou alvo?" foi apresentada a dificuldade em classificar orações nas quais o terceiro argumento é um constituinte formado por um substantivo que designa parte do corpo humano. Nas discussões via e-mail com Adler, a linguista considerou que orações como a representada a seguir denotariam posse causada:

(13) Cholecystokinin sendet Signale über den Vagusnerv ans Gehirn, der wiederum als Reaktion auf das Hormon im Darm Acetylcholin freisetzt (SPK/J05.01311 spektrumdirekt, 11.10.2005).

ADLER (2011) sustenta a abordagem sensitiva ao verbo de RAPPAPORT HOVAV e LEVIN (2008) e também discorre acerca do fato de a componente mudança de localização (Ortwechsel) fazer parte da semântica do verbo e não da construção. Dessa forma, segundo Adler, tem-se em todas as construções com o sintagma preposicional anuma combinação de movimento causado (devido ao radicaldo verbo) com posse causada (devido ao addresseean).

$\mathrm{Na}$ oração em (13), pode-se substituir o sintagma preposicional na pelo sintagma preposicional $z u$, na medida em que "cérebro" é ao mesmo tempo um lugar e um órgão que pode receber algo. Assim, a oração com o sintagma zu (Cholecystokinin sendet Signale über den Vagusnerv zum Gehirn) evidencia o órgão cérebro como um lugar no corpo, enquanto a oração com o sintagma preposicional $n a$ ressalta a propriedade do cérebro de receber algo. Ou seja, como Adler (2016) elucida, a escolha entre an e zu é influenciada de acordo com o componente que o falante quer enfatizar. Com a variante na ressalta-se a propriedade do cérebro de receptor e não o cérebro como um lugar no corpo.

Também foram enquadradas como um evento de posse causada as orações (1a) e (1b), uma vez que nenhuma delas pode ser reescrita com o advérbio locativo hin. Como abordado no início da análise, as orações constituídas por um tema abstrato 
Heluany, A. C. - Alternância dativa

foram classificadas inicialmente como construções de transferência de movimento causado, conforme Goldberg. Ressalta-se que, tendo em vista que para Goldberg essas construções apresentam a mesma semântica das construções bitransitivas ( $\mathrm{X}_{\text {CAUSA }} \mathrm{Y}_{\mathrm{A}}$ RECEBER Z), tem-se apenas uma diferença na nomenclatura empregada por GoLDBERG (1995) e ADLER (2011). Enquanto a primeira considera orações com ausência de movimento físico uma extensão metafórica da construção de movimento causado e, por isso, nomeia-as construção de transferência de movimento causado, a segunda enquadra essas orações no grupo dos eventos de posse causada.

As orações (14) e (15) também foram discutidas com Adler em troca de e-mails. Para ela, ambas denotam posse causada. Entretanto, devido ao fato de a oração (14) apresentar um sujeito volitivo e tal argumento estar ausente em (15), a explicação de Adler não pareceu suficiente para analisar as orações:

(14) Wenn wir nicht genügend Nahrung zu uns nehmen, sendet unser Organismus an verschiedene Organe ein Hungersignal.

(15) Die Kapsel sendet ständig Aufnahmen aus dem Körperinnern an sechs Sensoren, die zuvor auf den Bauch des Patienten geklebt wurden.

Levando-se em consideração que "a cápsula" não é um sujeito animado, questiona-se a adequabilidade de classificar a oração como um evento de posse causada, na medida em que não há um possuidor a priori e, dessa forma, não há um argumento agente capaz de transferir algo para alguém. Diante dessas indagações, buscou-se na literatura sobre Gramática de Construções preceitos teóricos que pudessem elucidar construções desprovidas de agente volitivo, como será apresentado no próximo item.

\subsection{Evento causal como transferência}

Conforme mencionado ao longo da análise, orações destituídas de agente volitivo suscitaram questionamentos. A seguir, serão analisadas algumas construções que não apresentam um sujeito animado e, por conseguinte, cujos sujeitos não possuem controle do evento:

(16) Der 15-jährige Schüler hatte ein elektronisches, „unüberwindbares“ Fahrradschloss entwickelt, das Alarmsignale an das Mobiltelefon des Besitzers 
sendet, wenn jemand versucht, das Schloss aufzubrechen (BRZ08/OKT.03911 Braunschweiger Zeitung, 08.10.2008).

Das Glutamat sendet Signale an das Gehirn, die nach Darstellung der Wissenschaftler vor allem eins aussagen: Mehr davon! Was genau geschehe, sei noch nicht erforscht (A97/JUL.12791 St. Galler Tagblatt, 03.07.1997).

As construções em (16) e (17) são semelhantes às construções em (3b), (7), (15) e (13) no que concerne ao sujeito. O fato de essas orações não possuírem um sujeito que participa ativamente do processo (Fahrradschloss, das Glutamat, Die Kleidung, Das verkürzte Protein, Die Kapsel, Cholecystokinin,) é uma das causas que geram dúvidas no que concerne à classificação dos papéis argumentais que constituem as referidas orações. Questiona-se se é adequado classificar "o cadeado da bicicleta", "o glutamato", "a roupa", "proteína reduzida", "a cápsula", "colecistocinina" como "enviadores" (Sender) de seus respectivos argumentos TEMA. Tendo em vista que eles são sujeitos inanimados, não se pode dizer que têm controle do evento e, portanto, eles não são os agentes das respectivas orações, mas sim os iniciadores do evento.

Consoante Goldberg, o padrão estrutural S V OBJ $\mathrm{OBJ}_{2}$ tem o seu sentido central de transferência concreta estendido de modo a cobrir outros significados (cf. GOLDBERG 1995:145). Para explicar a relação de herança entre construções, Goldberg postula princípios psicológicos de organização da linguagem. Um desses princípios é o da economia maximizada, o qual estabelece que o número de construções distintas deve ser minimizado tanto quanto for possível (GOLDBERG 1995: 67).

Assim, as instanciações oracionais com o formato $\mathrm{S} V \mathrm{OBJ} \mathrm{OBJ}_{2}$ não apresentam todas as propriedades da construção bitransitiva, já que o agente nem sempre é um ser animado e, portanto, é incapaz de transferir algo intencionalmente. Da mesma forma, o OBJ nem sempre é um objeto concreto que possa ser transferido para um recipiente humano e o $\mathrm{OBJ}_{2}$ nem sempre representa o papel semântico de recipiente bem definido.

Com base nisso, na oração em (16) tem-se um sujeito inanimado (das [Fahrradschloss]) e um argumento TEMA abstrato (Alarmsignale). Fahrradschloss é inanimado e, portanto, não intencional. Goldberg atribui casos como estes à metáfora convencional e sistemática eventos causais como transferências. Por meio dessa 
Heluany, A. C. - Alternância dativa

metáfora, causar um evento em uma entidade é entendido como transferir o efeito, construído como um objeto, para essa entidade (cf. GOLDBERG 1995: 144).

Dessa forma, nota-se que a oração em (16) não deve ser analisada como uma construção na qual o agente pretende causar o recipiente a receber o paciente, mas sim como um evento causal de transferência, no qual $X_{\text {CAUSA }} Y_{\text {(AFETADO) A RECEBER } Z}$ (EFEITO).

Em (16), o cadeado da bicicleta é um agente involitivo (sem vontade própria) e por isso não pode ser "possuidor" de algo e nem é capaz de aplicar uma força (X) capaz de fazer com que algo (Y) se mova para um alvo (Z). Portanto, a construção não apresenta nem evento de movimento causado, nem evento de posse causada, pois o sujeito não participa ativamente, mas é apenas iniciador do evento. Assim, pode-se descrever a oração em (16) da seguinte forma: o "cadeado da bicicleta" é o iniciador do evento, o qual envia um "sinal de alarme" (efeito) para o dono do celular (afetado). E em (17), de modo semelhante, o glutamato é o iniciador do evento (causa), que faz com que o cérebro (afetado) receba o sinal (efeito).

Da mesma forma, em (7), a proteína reduzida não está apta a detectar componentes bacterianos muito pequenos e, em consequência disso, envia poucos mensageiros ao sistema imunológico. Ou seja, a causa de o sistema imunológico não receber sinais suficientes consiste no fato de a proteína não reconhecer de forma eficaz os componentes bacterianos e, por sua vez, o efeito disso é que o sistema imunológico (afetado) recebe poucos neurotransmissores (efeito).

Analogamente, tem-se para a oração em (3b) a roupa como iniciadora do evento de enviar sinais não verbais às pessoas, ou seja, a causa que faz com que as pessoas (afetado)recebam esses sinais (efeito). Em (13), a colecistocinina é o que causa o cérebro (afetado) a receber o sinal (efeito) transmitido pelo nervo; e em (15) tem-se a cápsula como causado envio de constantes gravações do interior do corpo (efeito) para os seis sensores (afetado).

Mediante o exposto, as orações mencionadas podem ser representadas da seguinte forma:

(16’) Der 15-jährige Schüler hatte ein elektronisches, „unüberwindbares“ Fahrradschloss (CAUSA) entwickelt, das Alarmsignale (EFEITO) an das Mobiltelefon des Besitzers (AFETADO) sendet, wenn jemand versucht, das Schloss aufzubrechen. 
(17') Das Glutamat (CAUSA) sendet Signale (EFEITO) an das Gehirn (AFETADO), die nach Darstellung der Wissenschaftler vor allem eins aussagen: Mehr davon! Was genau geschehe, sei noch nicht erforscht.

(3b') Die Kleidung (CAUSA) sendet nonverbale Signale (EFEITO) an jeden Menschen (AFETADO), dem ich begegne.

(7’) Das verkürzte Protein (CAUSA) aber kann bakterielle Bestandteile nur ungenügend erkennen und sendet zu wenig chemische Botenstoffe (EFEITO) an das Immunsystem. (AFETADO)

(15') Die Kapsel (CAUSA) sendet ständig Aufnahmen aus dem Körperinnern (EFEITO) an sechs Sensoren (AFETADO), die zuvor auf den Bauch des Patienten geklebt wurden.

(13') Cholecystokinin (CAUSA) sendet Signale (EFEITO) über den Vagusnerv ans Gehirn (AFETADO), der wiederum als Reaktion auf das Hormon im Darm Acetylcholin freisetzt.

Diante dessas considerações, sugere-se que, para a análise de orações destituídas de agente volitivo, não é adequada a classificação das construções em evento de posse causada e evento de movimento causado. Isto posto, propõe-se que as construções nas quais não existe um sujeito volitivo sejam analisadas como evento causal como transferência, com os papéis argumentais de causa, afetado e efeito.

\section{Conclusões}

Conforme demonstrado ao longo da análise, a distinção entre recipiente e alvo e, por conseguinte, entre evento de posse causada e movimento causado, é ambígua em muitas ocorrências. Isso consiste no fato de o verbo senden ter tanto um significado espacial quanto um significado possessivo. 
Heluany, A. C. - Alternância dativa

A ambiguidade constatada na classificação dos argumentos ocorrentes com o verbo senden demonstrou que as reflexões de GOLDBERG (1995) sobre recipiente não são suficientes para análise de construções da língua alemã com verbos que denotam eventos de transferência. Conforme discutido ao longo da análise, Goldberg parte da premissa de que a construção bitransitiva impõe a restrição de que o papel send.goal deve ser um recipiente e, por isso, animado. Entretanto, tal imposição revela lacunas no momento de classificar o evento presente em determinadas construções com constituintes como an die Zentrale, an die Universität, an die Heimat, não sendo possível distinguir com clareza se se trata de um evento de posse causada ou de movimento causado tendo como base apenas as considerações da autora.

Diante das dificuldades apresentadas foram buscadas outras abordagens baseadas na Gramática de Construções para analisar a alternância dativa no inglês, como a "Teoria da sensitividade ao núcleo verbal" de RAPPAPORT HOVAV E LEVIN (2008). Para as autoras, verbos pertencentes ao grupo enviar podem denotar na construção com o sintagma preposicional tanto um evento de posse causada quanto um evento de movimento causado.

Os estudos de ADLER (2011) corroboram as dificuldades abordadas no tópico referente à distinção entre evento de posse causada e evento de movimento causado com verbos do grupo prototípico senden. A autora também se vale dos preceitos de RAPPAPORT HOVAV e LEVIN (2008) sobre o fato de o componente semântico mudança de localização fazer parte do radical do verbo e não da construção.

Dessa forma, Adler, ao comparar verbos do grupo prototípico dar com verbos do grupo jogar e enviar, observa que o advérbio locativo hin pode ser empregado apenas em verbos cuja construção denota um evento de movimento causado: David schickte das Paket zu seiner / *na seine Mutterhin. Devido ao fato de o an locativo ser usualmente incompatível com complementos animados, a autora assume que a preposição an que aparece em eventos de transferência de posse é um addressee-an específico, constituindo assim uma faceta separada do significado da preposição an.

Com base nas considerações de Adler, o HIN-Test foi utilizado para reanalisar as orações discutidas no tópico “Recipiente ou alvo?”.Com isso, foi possível demonstrar que a maior parte delas designa um evento de posse causada, corroborando assim as premissas de Adler sobre o addressee-an. 
Heluany, A. C. - Alternância dativa

Além disso, esta pesquisa evidenciou que o argumento TEMA desempenha um papel fundamental na realização dos argumentos e na consequente classificação do tipo de evento denotado pela construção. Como mencionado, argumentos abstratos não se enquadram nos eventos de movimento causado, uma vez que não podem percorrer uma trajetória. Este resultado foi corroborado por Adler, que também discorreu a respeito.

A proposta de Adler (2011), que postula que as construções com verbos do grupo enviar denotam, na variante com o sintagma preposicional, um evento de posse causada devido ao addressee-na, se mostrou a mais adequada das abordagens utilizadas para análise do corpus desta pesquisa.

Além disso, constatou-se que o papel de agente também é crucial para a classificação semântica do evento denotado pela construção. Se não há um agente volitivo, não se pode dizer que alguém foi responsável por aplicar uma força $(\mathrm{X})$ capaz de fazer com que algo (Y) se mova para um alvo (Z). Da mesma maneira, um agente involitivo não possui algo (Y) a priori, não podendo, por conseguinte, transferir algo. Isto posto, concluiu-se que ele designa o iniciador do evento.

Assim, essa pesquisa contribui para os estudos na área de realização dos argumentos, ao evidenciar que não são as variantes as responsáveis pelo evento denotado pela construção com verbos do grupo enviar, mas sim os argumentos (argumento TEMAe agente da oração) que a constituem.

Nova nesses estudos é a proposta de incluir outro tipo de classificação para verbos que denotam eventos de transferência em orações destituídas de agente volitivo: evento causal como transferência, no qual X CAUSA Y (AFETADO) A RECEBER Z (EFeito), evidenciando assim que não só o argumento TEMA, como também o agente da oração desempenha um papel fundamental na representação semântica da construção.

\section{Referências bibliográficas}

ADLER, Julia. Dative Alternations in German: The Argument Realization Options of Transfer Verbs. 2011. 271 f. Tese (Doutorado em Filosofia) -Hebrew University, Jerusalem, 2011. Disponível em: 〈http://arad.mscc.huji.ac.il/dissertations/W/JMS/001891760.pdf〉. Acesso em: 16 ago. 2016.

DORIS L.; BARSHI, Immanuel. (Eds.). External Possession. Amsterdam, John Benjamins,1999. p. 109-135 apud ADLER, Julia. Dative Alternations in German: The Argument Realization Options of Transfer Verbs. 2011. 271 f. Tese (Doutorado em 
Filosofia) - Hebrew University, Jerusalem, 2011. Disponível em: <http://arad.mscc.huji.ac.il/dissertations/W/JMS/001891760.pdf>. Acesso em: 16 ago. 2016. p. 4.

Engelen, Bernhard. Untersuchungen zu Satzbauplan und Wortfeld in der geschriebenen deutschen Sprache der Gegenwart. Munich: Hueber, 1975. v. 2.

FERRARI, Lilian. Introdução à Linguística Cognitiva. São Paulo: Contexto, 2011.

Goldberg, Adele Eva. Constructions: A Construction Grammar Approach to Argument Structure. Chicago: University of Chicago Press, 1995.

Haspelmath, Martin. External Possession in a European Areal Perspective. In: PAYNE,

HeluAnY, Anna Carolina de Jesus Barbosa. Alternância dativa sob a perspectiva da gramática de construções: uma análise do verbo senden. 2017. Dissertação (Mestrado em Língua e Literatura Alemã) - Faculdade de Filosofia, Letras e Ciências Humanas, Universidade de São Paulo, São Paulo, 2016. Disponível em: <http://www.teses.usp.br/teses/disponiveis/8/8144/tde-07062017-091928>. Acesso em: 18 jun. 2017.

INSTITUT FÜR DEUTSCHE SPRACHE. Valenzwörterbuch: E-Valbu. Disponível em:〈http://hypermedia.ids-mannheim.de/evalbu/index.html〉. Acesso em: 15 jun. 2017.

KRIFKA, Manfred. Manner in Dative Alternation. Proceedings of the West Coast Conference on Formal Linguistics (WCCFL 18).Somerville (MA): Cascadilla Press, 1999. p. 260-271.

MATZEL, Klaus. Dativ und Präpositionalphrase.Sprachwissenschaft, v. 1, p. 144-186, 1976.

MUSAN, Renate. Informationsstruktur. Heidelberg:Universitätsverlag Winter, 2010.

RAPPAPORT Hovav, Malka; LEvin, Beth. The English dative alternation: The Case for Verb Sensitivity. Journal of Linguistics, v. 44, p. 129-167, 2008.

SoARes, Eduardo Correa; MENuZzi, Sérgio de Moura. Introduzindo e problematizando papéis temáticos e hierarquias temáticas: uma questão de interfaces. Santa Cruz do Sul: Signo, $2010 . \quad$ Disponível em: $\langle$ https://online.unisc.br/seer/index.php/signo/article/viewFile/1432/1256>. Acesso em: 16 ago. 2016.

SUCHAROWSKI, Wolfgang. Der Dativ und seine präpositionalen Varianten als Kasusparaphrasen. Überlegungen $\mathrm{zu}$ einem allgemeineren Kasusbegriff. Grazer Linguistische Studien, v. 42, p. 99-114, 1994.

Wegener, Heide. Der Dativ im heutigen Deutsch.Tübingen: Narr, 1985.

WundERLICH, Dieter. Towards a Structural Typology of Verb Classes. Advances in the Theory of the Lexicon. Berlin: Walter de Gruyter, 2005.

ZIEM, Alexander; LASCH, Alexander. Konstruktionsgrammatik: Konzepte und Grundlagen gebrauchsbasierter Ansätze. Berlin: De Gruyter, 2013. 